\title{
Jena Reference Air Set (JRAS): a multi-point scale anchor for isotope measurements of $\mathrm{CO}_{2}$ in air
}

\author{
M. Wendeberg, J. M. Richter, M. Rothe, and W. A. Brand \\ Max Planck Institute for Biogeochemistry Jena, P.O. Box 100164, 07701 Jena, Germany \\ Correspondence to: W. A. Brand (wbrand@bgc-jena.mpg.de) \\ Received: 30 July 2012 - Published in Atmos. Meas. Tech. Discuss.: 13 September 2012 \\ Revised: 7 March 2013 - Accepted: 8 March 2013 - Published: 26 March 2013
}

\begin{abstract}
The need for a unifying scale anchor for isotopes of $\mathrm{CO}_{2}$ in air was brought to light at the 11th WMO/IAEA Meeting of Experts on Carbon Dioxide in Tokyo 2001. During discussions about persistent discrepancies in isotope measurements between the worlds leading laboratories, it was concluded that a unifying scale anchor for Vienna Pee Dee Belemnite (VPDB) of $\mathrm{CO}_{2}$ in air was desperately needed. Ten years later, at the 2011 Meeting of Experts on Carbon Dioxide in Wellington, it was recommended that the Jena Reference Air Set (JRAS) become the official scale anchor for isotope measurements of $\mathrm{CO}_{2}$ in air (Brailsford, 2012).

The source of $\mathrm{CO}_{2}$ used for JRAS is two calcites. After releasing $\mathrm{CO}_{2}$ by reaction with phosphoric acid, the gases are mixed into $\mathrm{CO}_{2}$-free air. This procedure ensures both isotopic stability and longevity of the $\mathrm{CO}_{2}$. That the reference $\mathrm{CO}_{2}$ is generated from calcites and supplied as an air mixture is unique to JRAS. This is made to ensure that any measurement bias arising from the extraction procedure is eliminated. As every laboratory has its own procedure for extracting the $\mathrm{CO}_{2}$, this is of paramount importance if the local scales are to be unified with a common anchor.

For a period of four years, JRAS has been evaluated through the IMECC ${ }^{1}$ program, which made it possible to distribute sets of JRAS gases to 13 laboratories worldwide. A summary of data from the six laboratories that have reported the full set of results is given here along with a description of the production and maintenance of the JRAS scale anchors.
\end{abstract}

\footnotetext{
${ }^{1}$ IMECC refers to the EU project "Infrastructure for Measurements of the European Carbon Cycle" (http://imecc.ipsl.jussieu.fr/).
}

\section{Introduction}

\subsection{State of affairs}

Prior to the 11th WMO/IAEA Meeting of Experts on Carbon Dioxide in Tokyo 2001, a project funded by the International Atomic Energy Agency (IAEA) called CLASSIC (Circulation of Laboratory Air Standards for Stable Isotope inter-Comparisons) had revealed significant discrepancies between four of the world's leading laboratories (Allison et al., 2003). The results from the CLASSIC project were based on five high-pressure cylinders filled with chemically modified air and two canisters with pure $\mathrm{CO}_{2}$. These gases had been circulated during two campaigns (19961998, 1999-2000) between CMAR/CSIRO ${ }^{2}$ (Aspendale, Australia), INSTAAR/NOAA (Boulder, USA), Scripps Institution of Oceanography (La Jolla, USA), and the Center for Atmospheric and Oceanic Studies at Tohoku University (TU), Sendai, Japan.

The results reported from the pure $\mathrm{CO}_{2}$ canisters exposed differences between the laboratories exceeding the interlaboratory target precision of $0.01 \%$ for $\delta^{13} \mathrm{C}$, leading the authors of the report to state: "The mean differences in reported values are consistent with uncertainties in assignment of the isotopic composition of in-house pure $\mathrm{CO}_{2}$ working standards onto the VPDB $\mathrm{CO}_{2}$ scale".

For the analysis of air in the high pressure cylinders, the results were not much better. Although the differences between two campaigns within the laboratories met the target precision, the average differences relative to the CMAR/CSIRO results for $\delta^{13} \mathrm{C}$ between the laboratories ranged from -0.022 to $+0.118 \%$ and for $\delta^{18} \mathrm{O}$ the range

\footnotetext{
${ }^{2}$ See Table 1
} 
Table 1. Laboratories that participated in the JRAS project.

\begin{tabular}{lll}
$\begin{array}{l}\text { Laboratoire des Sciences du Climat et de l'Environnement (LSCE) } \\
\text { Department of Environmental Physics - AGH-University of Science } \\
\text { and Technology }\end{array}$ & $\begin{array}{l}\text { Gif sur Yvette Cedex } \\
\text { Kraków }\end{array}$ & $\begin{array}{l}\text { France } \\
\text { Poland }\end{array}$ \\
$\begin{array}{l}\text { Institute of Environmental Physics - University of Heidelberg (UH-IUP) } \\
\text { Scripps Institution of Oceanography - University of }\end{array}$ & $\begin{array}{l}\text { Heidelberg } \\
\text { La Jolla }\end{array}$ & Germany \\
$\begin{array}{l}\text { California-San Diego (SIO) } \\
\text { CSIRO - Center for Marine and Atmospheric Research } \\
\text { (CMAR/CSIRO) }\end{array}$ & Aspendale, Victoria & Australia \\
$\begin{array}{l}\text { Environment Canada - Stable Isotope Research Laboratory (EC) } \\
\text { National Institute for Environmental Studies (NIES) }\end{array}$ & $\begin{array}{l}\text { Downsview Ontario } \\
\text { Institute for Reference Materials and Measurements (IRMM) }\end{array}$ & Canada \\
$\begin{array}{l}\text { Climate and Environmental Physics - University of Bern (UB) } \\
\text { Institute of Arctic and Alpine Research - University of Colorado } \\
\text { (INSTAAR/NOAA) }\end{array}$ & $\begin{array}{l}\text { Geel } \\
\text { Benter for Atmospheric and Oceanic Science - Indian Institute of }\end{array}$ & Boulder, Colorado \\
$\begin{array}{l}\text { Science (IIS) } \\
\text { Max Planck Institute for Biogeochemistry (MPI-BGC) }\end{array}$ & Bangalore & USA \\
$\begin{array}{l}\text { National Institute of Water and Atmospheric Research (NIWA) } \\
\text { India }\end{array}$ & Jena & $\begin{array}{l}\text { Germany } \\
\text { Wellington }\end{array}$ \\
\hline
\end{tabular}

was -0.804 to $+0.112 \%$. Quoting the report: "As with $\mathrm{GS}_{20 \mathrm{~B}}{ }^{3}$, the mean difference between laboratories is consistent with problems in assignment onto the VPDB- $\mathrm{CO}_{2}$ reference scale".

At the root of this problem was and still is the fact that both methods for scale anchoring and the choice of anchor vary from laboratory to laboratory. A further complicating factor was that all available scale anchors were pure $\mathrm{CO}_{2}$, thus forcing the laboratories to anchor their scales by comparing the $\mathrm{CO}_{2}$ they extracted from air to pure reference $\mathrm{CO}_{2}$ - a comparison that adds any possible bias caused by the extraction of $\mathrm{CO}_{2}$ from air to the local scale. As the extraction method is unique to the laboratory, the resulting local scale will hence differ from laboratory to laboratory.

In addition to this weakness in scale definition, results were hampered by the cross-contamination or eta effect that has been plaguing isotope mass spectrometers over years (Meijer et al., 2000; Verkouteren et al., 2003a, b) and, thus, causing scale contraction. Further inconsistencies were found in the correction procedures for the ${ }^{17} \mathrm{O}$ contribution used when translating ion currents into delta values (Brand et al., 2010) and in the algorithms applied for removing the inevitable presence of $\mathrm{N}_{2} \mathrm{O}$ in the $\mathrm{CO}_{2}$ gas extracted from air cryogenically (Sirignano et al., 2004; Ghosh and Brand, 2004).

\subsection{The Jena Reference Air Set - JRAS}

A JRAS set consists of two $5 \mathrm{~L}$ glass flasks containing $\mathrm{CO}_{2}$ from two different calcites mixed into $\mathrm{CO}_{2}$-free air. Reference gases are problematic to store and keep unaltered regarding the isotopic composition. For reliable longterm stability, solid (or liquid) materials are preferred. For

\footnotetext{
${ }^{3}$ One of the two pure $\mathrm{CO}_{2}$ canisters.
}

the carbon and oxygen isotopes, the internationally available and agreed upon primary reference materials are carbonates: NBS 19 with $\delta^{13} \mathrm{C}_{\mathrm{VPDB}}=+1.95 \%$ and LSVEC with $\delta^{13} \mathrm{C}_{\mathrm{VPDB}}=-46.6 \%$ (Coplen et al., 2006). By also using solid calcites for anchoring the air- $\mathrm{CO}_{2}$ scale, enough material can be prepared and stored without risk of isotopic alteration to ensure both longevity and stability of the JRAS scale anchors. The first of the two calcites, MAR-J1, with $\delta^{13} \mathrm{C}_{\mathrm{VPDB}} \sim+2 \%$, has characteristics (isotopic composition, trace elements, grain size) that are almost identical to NBS 19, the primary scale anchor for Vienna Pee Dee Belemnite (VPDB). The second calcite, OMC-J1, is also similar to NBS 19, but not as close as MAR-J1 (see Ghosh et al., 2005). It was chosen as a compromise after a long and unsuccessful search for an ideal candidate to serve as a second anchor point to the VPDB isotope scale. Ideally, this point should be close to that of atmospheric $\mathrm{CO}_{2}$; however, OMC$\mathrm{J} 1$ provides an adequate range between the two anchor points with a $\delta^{13} \mathrm{C}$ value of about $-4 \%$ on the VPDB scale (Ghosh et al., 2005).

In order to keep the variability arising from the preparation of the reference $\mathrm{CO}_{2}$ at a minimum, a computer-controlled system has been designed and built at the MPI-BGC stable isotope facility (Ghosh et al., 2005). The system prepares $\mathrm{CO}_{2}$ by digestion of the calcites in highly concentrated phosphoric acid and mixes it into $\mathrm{CO}_{2}$-free air in batches large enough to provide three $5 \mathrm{~L}$ flasks ( $p=1.5 \mathrm{bar}$ ) at a time. The $\delta^{13} \mathrm{C}$ scale at the BGC Isolab has been established by repeated analysis of preparations of the primary calcites, NBS 19 and LSVEC, using the automated preparation system (Ghosh et al., 2005; Brand et al., 2009). This scale, JRAS-06, which is firmly anchored at $+1.95 \%$ and $-46.6 \%$ exactly and is continuously maintained, has been 

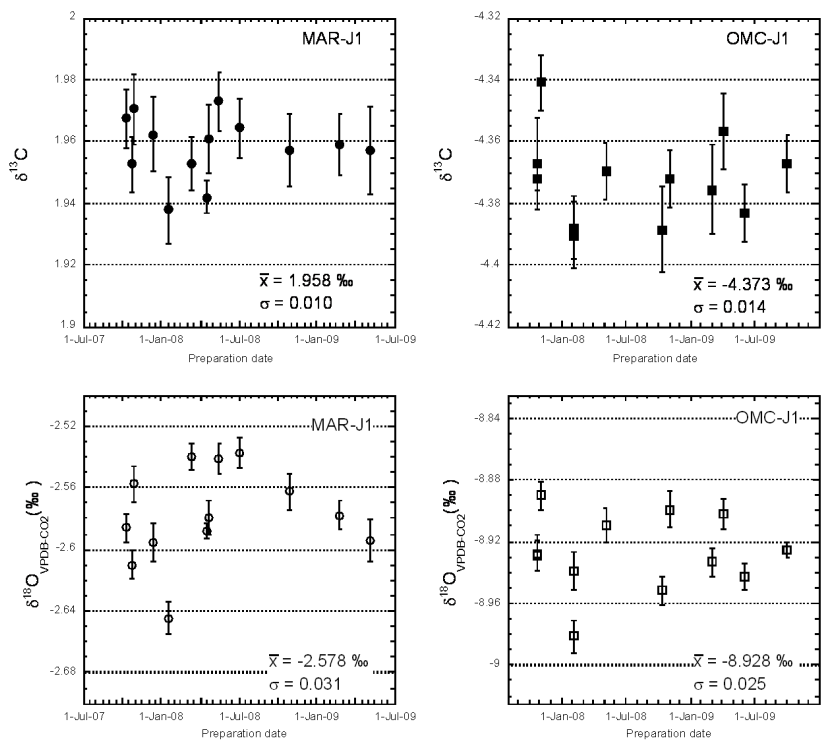

Fig. 1. Production variability of the JRAS gases over time. Each data point represents an average of nine measurements of the prepared $\mathrm{CO}_{2}$-air mix, three per flask within a batch. Thus the overall standard deviation $(1 \sigma)$ reflects the combined variability between the prepared $\mathrm{CO}_{2}$ as well as the uncertainty related to the extraction and mass spectrometric measurements performed in the MPI-BGC laboratory.

Table 2. $\delta^{13} \mathrm{C}$ results. Linear regression resulting from comparing local scales to JRAS-06.

\begin{tabular}{lrrr}
\hline & \multicolumn{3}{c}{$y=a+b x$} \\
\cline { 2 - 4 } & $a$ & $b$ & $R^{2}$ \\
\hline INSTAAR, University of Colorado, USA & -0.0721 & 0.9836 & 0.99997 \\
NIES, Japan & -0.0199 & 0.9963 & 1 \\
Scripps Institution of Oceanography, USA & -0.1198 & 0.9795 & 0.99999 \\
University of Heidelberg, Germany & -0.0321 & 1.0016 & 0.99999 \\
NIWA, New Zealand & 0.0503 & 1.0026 & 0.99994 \\
MPI-BGC, Germany & 0.0007 & 0.9992 & 1 \\
\hline
\end{tabular}

used to assign the initial values of the JRAS sets before distribution.

Figure 1 shows the inter-batch $\delta^{13} \mathrm{C}$ variability of the produced $\mathrm{CO}_{2}$ between 2007 and 2009. These data provide the information regarding the maintenance and repeatability of the JRAS-06 scale over time. The preparations should not vary by a large amount in order to maintain the anchor point fixed in time. It is important to note that - because the isotopic composition of the flasks is measured and assigned during this procedure - the preparation variability is not propagated into an uncertainty of the scale anchor.

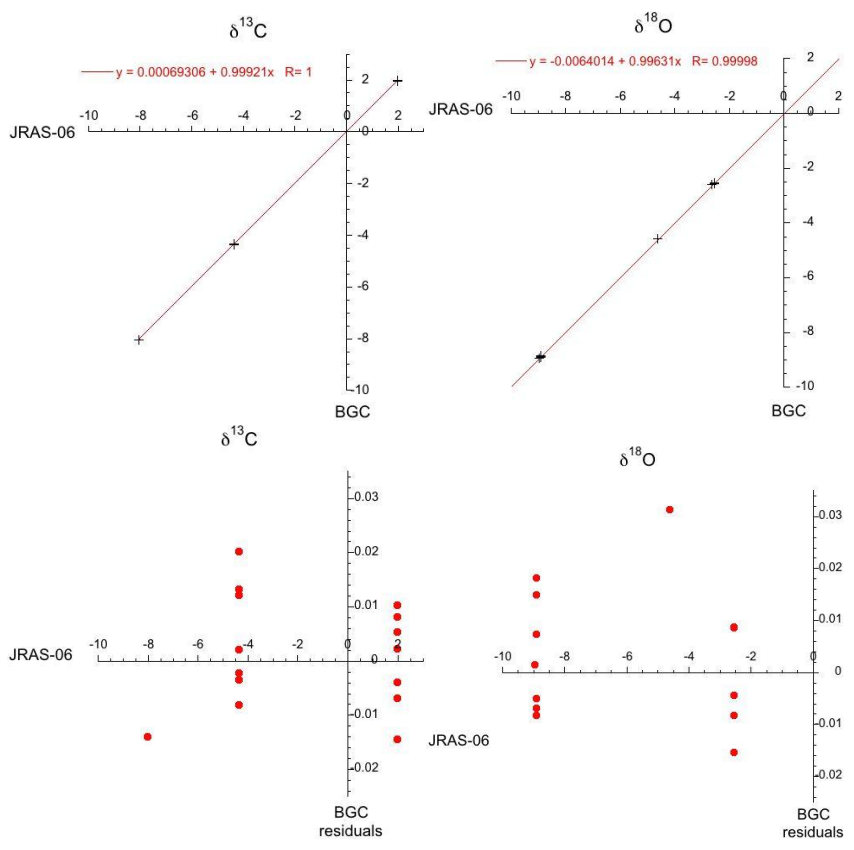

Fig. 2. Regression and residuals plots of MPI-BGC measurements $(n=15)$ of JRAS gases treated as independent samples to the originally assigned values on the JRAS-06 scale. Left panels show the $\delta^{13} \mathrm{C}$ data and right panels the corresponding $\delta^{18} \mathrm{O}$ data.

Table 3. $\delta^{18} \mathrm{O}$ results. Linear regression resulting from comparing local scales to JRAS-06.

\begin{tabular}{lrrr}
\hline & \multicolumn{3}{c}{$y=a+b x$} \\
\hline INSTAAR, University of Colorado, USA & $a$ & $b$ & $R^{2}$ \\
NIES, Japan & 0.0399 & 0.9667 & 0.99997 \\
Scripps Institution of Oceanography, USA & -0.09 & 0.9895 & 0.99999 \\
University of Heidelberg, Germany & 0.151 & 0.9426 & 0.99722 \\
NIWA, New Zealand & -0.0709 & 0.9549 & 0.99872 \\
MPI-BGC, Germany & -0.0064 & 0.9963 & 0.99998 \\
\hline
\end{tabular}

\section{Results}

\section{Test and evaluation}

The JRAS concept has been evaluated from 2007 to 2011 as a part of the European Commission funded program - Infrastructure for Measurements of the European Carbon $\mathrm{Cy}$ cle, IMECC. Thanks to IMECC the isotope laboratory at MPI-BGC has been able to produce and distribute 50 JRAS sets. Thirteen laboratories from all over the world volunteered to participate in the IMECC-JRAS project (Table 1). Each of the laboratories received a JRAS set which, when exhausted, was replaced with a new set. The number of analyses performed varied between the participating laboratories due to differences in workload and instrument availability. The project as a whole totaled over 250 analyses of the JRAS scale anchors. 


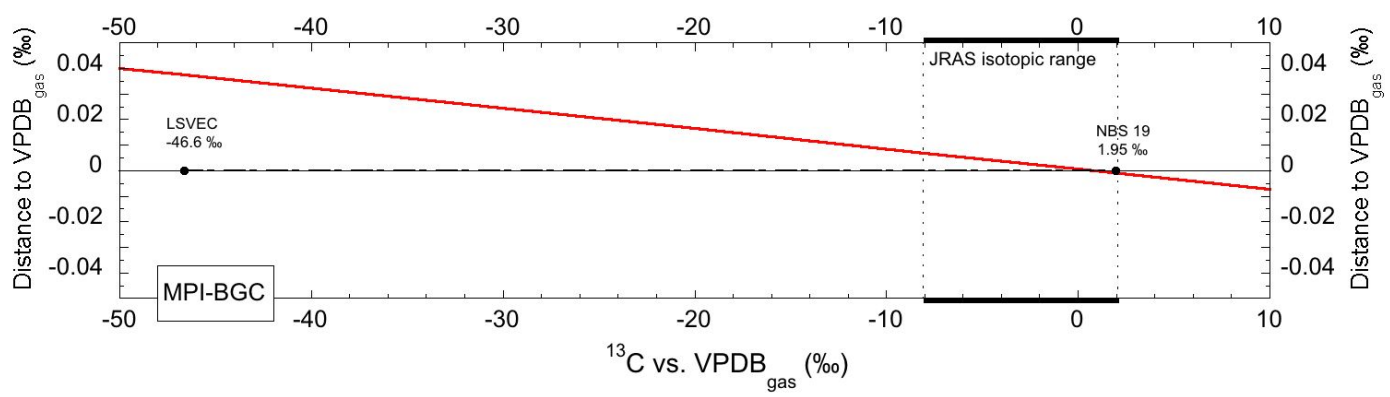

Fig. 3. Extrapolation of the MPI-BGC results presented in Fig. 2 to the isotopic range spanned by NBS 19 and LSVEC.

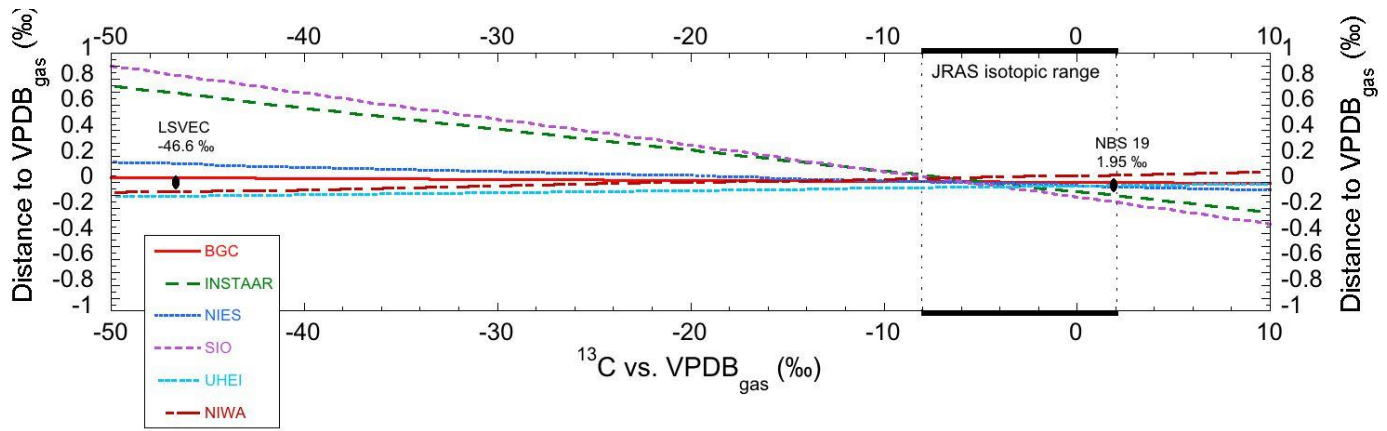

Fig. 4. Extrapolation based on linear regression of the JRAS $\delta^{13} \mathrm{C}$ data.

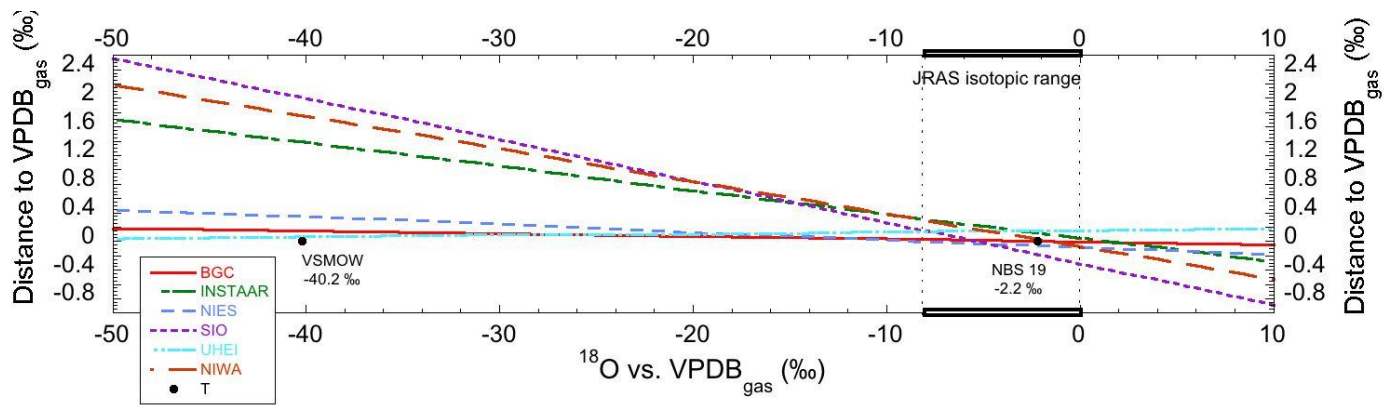

Fig. 5. Extrapolation based on linear regression of the JRAS $\delta^{18} \mathrm{O}$ data.

In the spring of 2010 the JRAS project was augmented with $5 \mathrm{~L}$ glass flasks containing calibrated (dry ambient) air; this was a result of requests made during discussions at the 15th WMO/IAEA Meeting of Experts on Carbon Dioxide in Jena 2009 (Brand, 2010). While these air samples do not constitute an immediate scale anchor (this is still exclusively made via the calcite materials MAR-J1 and OMC-J1), they add an important data point right at the isotope composition of atmospheric $\mathrm{CO}_{2}$, thus allowing for a three-point comparison of the local scale implementations.

We obtained complete data sets including the ambient air sample from only six of the thirteen laboratories. These JRAS results were evaluated by comparing the analytical results on the local scales with the values assigned on the JRAS-06 scale. MPI-BGC also participated in the evaluation by intermittently measuring JRAS gases as independent samples. These BGC results are shown in Fig. 2, where the (least square) linear regression represents the agreement between the round-robin measurements and the initial assignment results on the JRAS-06 scale. The additive term in the equation signifies an offset between the two sets of data, and the factor/slope describes differences in standardization strategies between laboratories or serves as a quantification of any scale contraction occurring. As both the term and the factor are negligible, the BGC results validate the ability of Isolab to maintain the JRAS-06 scale.

In Fig. 3 the BGC Isolab data presented in Fig. 2 are extrapolated to a wider delta scale, now covering the whole isotopic range of the two primary scale anchors, NBS 19 and LSVEC. This plot provides an enhanced visual characterization of scale discrepancies caused by different standardization schemes or possibly scale contraction issues. For MPIBGC, the deviation of the scale is insignificant, amounting to $0.04 \%$ only over a scale distance of almost $50 \%$. However, 
when we plot the results from all participating laboratories that included the air samples in their measurements, the deviations become more prominent (Table 2, Fig. 4).

In Fig. 4 the results from the different laboratories are extrapolated in the same fashion as shown in Fig. 3 for MPIBGC to demonstrate the relationship between the local scales and $\mathrm{VPDB}_{\text {gas. }}$. The offsets between local scales and VPDB$\mathrm{CO}_{2}$ (term $a$ in Table 2) determined by the JRAS project are not much different from those reported in the CLASSIC project. Hence, the situation has remained largely unchanged over the last decade. With the JRAS project the scale comparison is going further than during CLASSIC by using a multi-point scale anchor, thereby allowing to test the local scales for scale contraction issues. Scale contraction (i.e., the scale offset is linearly dependent on the delta value) can be caused by differences in standardization methods/materials or cross contamination in the mass spectrometer. The results from JRAS clearly suggest that these issues are real and significant (slope $b$ in Table 2), although not for all laboratories. For example, the factor $b$ values of the regressions for University of Heidelberg and NIWA are so small that the slope is insignificant, thus explaining the sign of the slopes, which otherwise would indicate a virtual scale expansion.

The results for oxygen isotopes can be evaluated in the same way as those for $\delta^{13} \mathrm{C}$. Here the offsets are expected to be larger, reflecting the commonly observed uncertainties in oxygen isotope measurements (Table 3, Fig. 5). Factors contributing to the uncertainty are the correction for $\mathrm{N}_{2} \mathrm{O}$ present in the analyzed gas (the correction for the $m / z 46$ ion current is larger than that for $m / z 45$; see Sirignano et al., 2004; Ghosh and Brand, 2004), the $\delta^{18} \mathrm{O}$ value used for digesting the calcite during standardization (Wendeberg et al., 2011) and the ${ }^{17} \mathrm{O}$ correction (Brand et al., 2010). The latter have been the focus of the WMO recommendations for several years, where the need for a unified use of the Assonov correction has been emphasized (Assonov et al., 2003).

\section{Conclusions}

Ten years after the need for a unifying scale anchor for $\mathrm{CO}_{2}$ in air was formulated, the participants of the 16th WMO/IAEA Meeting of Experts on Carbon Dioxide in Wellington 2011 have decided to recommend the JRAS gases for use as the official scale anchor for measurement of atmospheric $\mathrm{CO}_{2}$ on the VPDB scale (Brailsford, 2012). This along with a unified use of the ${ }^{17} \mathrm{O}$ correction will hopefully contribute greatly to harmonize the various local scales.

The MPI-BGC lab will continue to aid in this process, now as a WMO-endorsed Central Calibration Lab, by providing calibration for high-pressure tanks based on the JRAS procedure.
Acknowledgements. We would like to thank all participants in the various laboratories for extending their best efforts into this (rather tedious) endeavor. In particular we would like to acknowledge their openness in communicating their results to the general public. We are indebted to three reviewers, whose suggestions helped to clarify several issues and improved readability of the manuscript. For financial support, we are indebted to the EU-IMECC project. Without this support for funding flasks, tanks and providing financial support for M.W., this study would not have been possible.

The service charges for this open access publication have been covered by the Max Planck Society.

Edited by: A. C. Manning

\section{References}

Allison, C. E., Francey, R. J., White, J. W. C., Vaughn, B., Wahlen, M., Bollenbacher, A., and Nakazawa, T.: What have we learnt about stable isotope measurements from IAEA CLASSIC, in: Proceedings of the 11th WMO/IAEA Meeting of $\mathrm{CO}_{2}$ Experts, Tokyo 2001, WMO/GAW publication series, 148, 17-30, 2003.

Assonov, S. S. and Brenninkmeijer, C. A. M.: On the O-17 correction for $\mathrm{CO}_{2}$ mass spectrometric isotopic analysis, Rapid Commun. Mass Sp., 17, 1007-1016, 2003.

Brailsford, G. (Ed.): Expert Group Recommendations; 16th WMO/IAEA Meeting on Carbon Dioxide, Other Greenhouse Gases, and Related Measurement Techniques (GGMT-2011), in: WMO-GAW Report No. 206, Wellington, 1-31, available at: http://www.wmo.int/pages/prog/arep/gaw/gaw-reports. html, 2012.

Brand, W. A. (Ed.): Expert Group Recommendations; 15th WMO/IAEA Meeting on Carbon Dioxide, Other Greenhouse Gases, and Related Measurement Techniques (GGMT-2009), in: WMO-GAW Report No. 194, Jena, available at: http: //www.wmo.int/pages/prog/arep/gaw/gaw-reports.html (last access: 25 March 2013), 2010.

Brand, W. A., Huang, L., Mukai, H., Chivulescu, A., Richter, J. M., and Rothe, M.: How well do we know VPDB? Variability of delta C-13 and delta O-18 in $\mathrm{CO}_{2}$ generated from NBS19calcite, Rapid Commun. Mass Sp., 23, 915-926, 2009.

Brand, W. A., Assonov, S. S., and Coplen, T. B.: Correction for the $\mathrm{O}-17$ interference in delta(C-13) measurements when analyzing $\mathrm{CO}_{2}$ with stable isotope mass spectrometry (IUPAC Technical Report), Pure Appl. Chem., 82, 1719-1733, 2010.

Coplen, T. B., Brand, W. A., Gehre, M., Gröning, M., Meijer, H. A. J., Toman, B., and Verkouteren, R. M.: New guidelines for delta C-13 measurements, Anal. Chem., 78, 2439-2441, 2006.

Ghosh, P. and Brand, W. A.: The effect of $\mathrm{N}_{2} \mathrm{O}$ on the isotopic composition of air- $\mathrm{CO}_{2}$ samples, Rapid Commun. Mass Sp., 18, 1830-1838, 2004.

Ghosh, P., Patecki, M., Rothe, M., and Brand, W. A.: Calcite- $\mathrm{CO}_{2}$ mixed into $\mathrm{CO}_{2}$-free air: a new $\mathrm{CO}_{2}$-in-air stable isotope reference material for the VPDB scale, Rapid Commun. Mass Sp., 19, 1097-1119, doi:10.1002/rcm.1886, 2005.

Meijer, H. A. J., Neubert, R. E. M., and Visser, G. H.: Cross contamination in dual inlet isotope ratio mass spectrometer, Int. J. Mass Spectrom., 198, 45-61, 2000. 
Sirignano, C., Neubert, R. E. M., and Meijer, H. A. J.: $\mathrm{N}_{2} \mathrm{O}$ influence on isotopic measurements of atmospheric $\mathrm{CO}_{2}$, Rapid Commun. Mass Sp., 18, 1839-1846, 2004.

Verkouteren, R. M., Allison, C. E., Studley, S. A., and Leckrone, K. J.: Isotopic metrology of carbon dioxide. I. Interlaboratory comparison and empirical modeling of inlet equilibration time, inlet pressure, and ion source conductance, Rapid Commun. Mass Sp., 17, 771-776, 2003a.
Verkouteren, R. M., Assonov, S., Klinedinst, D. B., and Brand, W. A.: Isotopic metrology of carbon dioxide. II. Effects of ion source materials, conductance, emission, and accelerating voltage on dual-inlet cross contamination, Rapid Commun. Mass Sp., 17, 777-782, 2003b.

Wendeberg, M., Richter, J. M., Rothe, M., and Brand, W. A.: $\delta^{18} \mathrm{O}$ anchoring to VPDB: calcite digestion with 18O-adjusted orthophosphoric acid, Rapid Commun. Mass Sp., 25, 851-860, 2011. 